\title{
Free microvascular tissue transfer for the reconstruction of midfacial defects in oncological patients
}

\author{
Maria Archontaki ${ }^{1}$, Spyros D. Stavrianos ${ }^{2}$, Alexander D. Rapidis ${ }^{3}$ \\ ${ }^{1} \mathrm{MD}$, Plastic and Reconstructive Surgeon, Greek Anticancer Institute, “St. Savvas” Hospital, Athens, Greece \\ ${ }^{2}$ MD, Head \& Neck, Plastic and Reconstructive Surgeon, Greek Anticancer Institute, "St. Savvas" Hospital, Athens, Greece \\ ${ }^{3}$ MD, Ph.D, DDS, Professor of Oral \& Maxillofacial Surgery, Greek Anticancer Institute, “St. Savvas” Hospital, Athens, Greece
}

Correspondence:

Kedrinou 41

11522 Ampelokipi

Athens, Greece

marchontaki@web.de

Received: $23 / 09 / 2009$

Accepted: 24/12/2009

\author{
Archontaki M, Stavrianos SD, Rapidis AD. Free microvascular tissue \\ transfer for the reconstruction of midfacial defects in oncological pa- \\ tients. Med Oral Patol Oral Cir Bucal. 2010 Sep 1;15 (5):e746-51. \\ http://www.medicinaoral.com/medoralfree01/v15i5/medoralv15i5p746.pdf \\ Article Number: 3189 http://www.medicinaoral.com/ \\ (C) Medicina Oral S. L. C.I.F. B 96689336 - pISSN $1698-4447$ - eISSN: 1698-6946 \\ eMail: medicina@medicinaoral.com \\ Indexed in: \\ -SCI EXPANDED \\ -JOURNAL CITATION REPORTS \\ -Index Medicus / MEDLINE / PubMed \\ -EMBASE, Excerpta Medica \\ -SCOPUS \\ -Indice Médico Español
}

\begin{abstract}
This study reviews our experience with free microvascular tissue transfer for the repair of midfacial defects in surgical oncology.

From 2000 to 2008, eight patients with maxillectomy defects were immediately reconstructed using free flaps. Their clinical charts were retrospectively reviewed to record demographic data, ablative and reconstructive procedures, complications and outcome.

Free tissue transfer was successful in all patients, giving an overall success rate of $100 \%$. The mean follow-up time was 4 to 101 months ( $\mathrm{mr}: 43.8$ ). Three patients died from the disease giving a patient mortality of $30 \%$, while five patients are alive, free of disease and back to their normal daily activities. The restoration of function and improvement of patients' quality of life was a common feature in all our reconstructions.

The development of free tissue transfer has made surgical treatment of oncological patients with maxillectomy defects previously considered inoperable possible, improving at the same time their quality of life.
\end{abstract}

Key words: Midface, maxillectomy defect, free flap, reconstruction.

\section{Introduction}

The reconstruction of midface defects is a challenge for the plastic surgeon because the malignant diseases originating in the midface can extend beyond it to involve soft tissue or bone of contiguous regions. In the last 25 years, there was an evolution away from the constraints of multistaged flaps to free reconstructive flaps of increasing versatility and sophistication, making the microsurgical reconstruction the preferred method for treating post resection midfacial defects (1-3).
The free microvascular tissue transfer overcomes many of the limitations of previous types of musculocutaneous flaps. The robust circulation and high reliability of free flaps represent an important advantage of this type of reconstruction $(4,5)$. Some flaps can be also raised while the resection is still in progress, and the donor sites are generally well tolerated. Selected flaps can incorporate vascularized muscle or bone in good quantities and provide large areas of skin and subcutaneous tissue meeting the demands of the defect $(6,7)$. 
Therefore, free flaps are increasingly used to remedy problems in midface reconstructions, with the free rectus abdominis, fibular, radial forearm and scapula flaps being the most common flaps used (8-11).

We aim to report our experience in performing reconstructive surgery on eight patients, with midface defects after ablative oncologic surgery, with the use of various free microvascular tissue transfer procedures.

\section{Patients and Methods}

Between November of 2000 and December of 2008, 8 patients underwent midface resections followed by immediate microsurgical reconstruction at the Greek Anticancer Institute, "St Savvas" Hospital. All the patients were evaluated preoperatively by members of a surgical team consisting of a plastic surgeon and a maxillofacial surgeon. All procedures were intended for curative resection. All flap harvests and reconstructions were performed under the direction of a single surgeon. Clinical charts of all patients were reviewed to record demographic data, surgical procedures, complications and outcome. There were six males and two female patients with a mean age of 61 years (range 50-70 years). Of the eight oncological patients, the majority was treated for squamous cell carcinoma. Of the remaining patients, 1 had adenocystic carcinoma, 1 had basal cell carcinoma, and 1 had basosquamous carcinoma. Four patients were treated for recurrent or persistent disease. The ablative procedures included 5 subtotal maxillectomies and 3 total maxillectomies. Three of them required orbital exenteration for tumour excision while in one case a total rhinectomy was necessary (Table 1). The majority of defects following resection were large. All patients received radiation therapy, 4 preoperatively only and 4 postoperatively. Functional and aesthetic results were evaluated a minimum of 11 months postoperatively by direct examination of the patient. The parameters which were assessed were the speech, diet, as well as the restoration of facial symmetry and contour.

\section{Results}

All patients underwent immediate microvascular freeflap reconstruction following tumour resection. The average time for flap elevation was 1.5 hours and the average total operative time was 10 hours.

A myocutaneous rectus abdominis free flap was used for soft-tissue reconstruction and resurfacing of the palatal mucosa in 3 patients, an osteocutaneous radial forearm flap (ORFF) sandwich flap was used in 4 patients, while a latissimus dorsi flap in combination with scapula bone was used in 1 patient. A modified radical neck dissection was performed in 6 cases. The recipient vessels were most commonly the facial artery and internal jugular vein.

All the free flaps survived. In one case a re-exploration was necessary but the patient eventually did well. There were no major postoperative complications. In one patient there was a wound infection, bone exposure and eventually bone loss. One other patient experienced partial wound dehiscence 3 weeks postoperatively, which necessitated wound re-exploration to close the wound. There were no donor-site complications and no significant donor-site morbidity. Mean follow-up in these patients was 43.87 months (range, 4 to 101 months). One

Table 1. The data of the patients, the type of ablative surgery, the free flap selection and the follow-up time.

\begin{tabular}{|c|c|c|c|c|c|c|c|}
\hline & $\begin{array}{c}\text { Case } \\
\text { No }\end{array}$ & $\begin{array}{c}\text { Age/ } \\
\text { Sex }\end{array}$ & Tumour & Defect & Flap & $\begin{array}{c}\text { Type } \\
\text { Follow-up } \\
\text { time }\end{array}$ \\
\hline 1 & GM & $62 / \mathrm{F}$ & SCC Upper lip & $\begin{array}{c}\text { Subtotal Maxillectomy, } \\
\text { Upper lip Resection }\end{array}$ & ORFF Sandwich flap & II & $48 \mathrm{~m}$ \\
\hline 2 & KK & $65 / \mathrm{M}$ & Adenocystic Ca upper.jaw & Bilateral Maxillectomy & ORFF Sandwich flap & II & $8 \mathrm{y}+5 \mathrm{~m}$ \\
\hline 3 & AN & $60 / \mathrm{M}$ & SCC med canthus & $\begin{array}{c}\text { Total Maxillectomy, } \\
\text { Orbita exenteration }\end{array}$ & RA & IIIB & IIIB \\
\hline 4 & CA & $60 / \mathrm{M}$ & Basosquamous orbita & $\begin{array}{c}\text { Maxillectomy, Ethmoidectomy, } \\
\text { Orbita Exenteration }\end{array}$ & RA $+5 \mathrm{~m}$ \\
\hline 5 & MG & $70 / \mathrm{M}$ & SCC maxilla & $\begin{array}{c}\text { Bilateral Maxillectomy, } \\
\text { Rhinectomy, Upper Lip Resection }\end{array}$ & ORFF Sandwich flap & II & $4 \mathrm{y}+2 \mathrm{~m}$ \\
\hline 6 & GN & $50 / \mathrm{M}$ & SCC nose & Bilateral Maxillectomy & ORFF Sandwich flap & II & $12 \mathrm{~m}$ \\
\hline 7 & MA & $59 / \mathrm{M}$ & SCC nose & $\begin{array}{c}\text { Bilateral Maxillectomy, } \\
\text { Rhinectomy }\end{array}$ & Latissimus dorsi flap & II & $2 \mathrm{y}+2 \mathrm{~m}$ \\
\hline 8 & MN & $62 / \mathrm{F}$ & BCC Face, nose & $\begin{array}{c}\text { Bilateral Maxillectomy, } \\
\text { Rhinectomy, Orbita Exenteration }\end{array}$ & RA & IIIB & $4 \mathrm{~m}$ \\
\hline
\end{tabular}

M, male; F, female; SCC, squamous cell carcinoma; BCC, basal cell carcinoma; R.A., rectus abdominis free flap; ORFF, osteocutaneous radial forearm free flap; Y, year; $\mathrm{M}$, month. 
patient died nine months postoperatively because of tumour recurrence, of the remaining patients, 5 are presently being followed as outpatients.

Speech was considered normal in 5 cases and intelligible in three cases. The patients were able to speak well and eat soft solids without problems. All 3 patients with resection of the oral commissure had good to excellent oral competence and were able to completely retain both solid and liquid food inside the oral cavity without drooling. All patients were discharged without feeding tubes and are on a regular diet, while 2 of them can tolerate at least a soft diet. $87.5 \%$ of the patients consider their overall aesthetic result to be good (Table 2).

Table 2. The outcome of the patients who had microvascular reconstruction of midfacial defects.

\begin{tabular}{|c|c|c|c|c|c|}
\hline & $\begin{array}{c}\text { Case } \\
\text { No }\end{array}$ & Speech & Diet & $\begin{array}{c}\text { Aesthetic } \\
\text { Result }\end{array}$ & $\begin{array}{c}\text { Final } \\
\text { result }\end{array}$ \\
\hline 1 & GM & Intelligible & Soft & Good & Poor \\
\hline 2 & KK & Normal & Unrestricted & Excellent & Excellent \\
\hline 3 & AN & Intelligible & Soft & Good & Good \\
\hline 4 & CA & Normal & Unrestricted & Good & Good \\
\hline 5 & MG & Normal & Unrestricted & Fair & Fair \\
\hline 6 & GN & Intelligible & Unrestricted & Good & Good \\
\hline 7 & MA & Normal & Unrestricted & Good & Good \\
\hline 8 & MN & Normal & Unrestricted & Good & Good \\
\hline
\end{tabular}

\section{Discussion}

The most effective treatment for malignant diseases of the maxillary complex is widely admitted to be the adequate surgical clearance, followed by planned postoperative radiotherapy (12). On the other hand, since the advancement of microsurgical techniques, our approach to reconstruct such complex defects of the midface, especially in oncological patients has changed significantly. Free flaps allow the surgeon to transfer a variety of different tissues with very high success rates, as well as with reliability for the duration of the result, especially in case of oncological patients with the need of postoperative radiotherapy.

Nowadays, the patients receive immediate microsurgical reconstruction and maximum surgical treatment at the first presentation. This fact is related not only to the advancement of reconstructive flap technology but also to the development of imaging techniques (Computed Tomography scans, Magnetic Resonance Imaging scans, flexible fiberoptic nasendoscopy) which allow early identification of recurrences, diminishing the need to inspect the resection bed directly (8).

Reconstruction of the midface has to fulfil multiple tasks, as many authors have emphasized, including sealing of the oral and nasal cavity from the skull base and orbit, reconstruction of the orbital floor or obliteration of the orbital cavity following orbital exenteration, obliteration of the maxillectomy defect, reconstruction of the intraoral, cheek and nasal lining to restore speech, mastication and oral continence and reconstruction of three-dimensional facial contour (4, 13-16).

The approach of such complex defect may be subdivided in reconstruction of individual structures treated as part of the overall defect, starting with the bony defect, followed by the associated soft-tissue, skin deficits and finally treating critical functional structures such as the oral commissure, nasal airway and eyelids (1).

According to Cordeiro et al. (1), the most widely accepted classification system of maxillary defects with reconstructive applications is based on the concept of the maxilla as a six-sided box or hexahedrium. It has been described by several authors, with regard to tumour ablation, determining the missing walls which must be reconstructed (17-21).

In our series the post resection defects were of type II (5 patients), and type IIIB (3 patients).

Subtotal maxillectomy defects (Type II) include resection of the maxillary arch, palate, anterior and lateral walls (lower five walls), with preservation of the orbital floor. Total maxillectomy defects (Type IIIB) include resection of all six walls of the maxilla in combination with exenteration of the orbital contents.

Many factors need to be weighted before the surgeon decides which individualized reconstructive procedure to recommend in a particular situation. These factors are related to the patient (age, comorbidities, etc), to the tumour (site, stage, etc), to the donor-site (deficiency in local vascular circulation, unacceptably high cosmetic penalty, etc), to the defect (size, local defects of previous radiation therapy or surgery, etc), or to the flap (flap skin characteristics, pedicle length and vessel diameter etc). The reconstructive options of the midface generally include regional pedicled flaps and free flaps. Four regional pedicled flaps were frequently used as soft-tissue carriers in the midface reconstruction because they can readily reach to the lower and mid-face: the temporalis, the pectoralis major, deltopectoral and extended trapezius flaps $(8,11,15)$. According to the current trend, free flaps represent an important option in reconstruction of midfacial defects and have been proved safe and effective.

The main characteristic of a free flap that is ideal for reconstruction of midface defects represents the 10- to $13-\mathrm{cm}$ long pedicle, in order to reach the neck without vein grafting (22). In addition to long vessels, the flap must provide critical ratios of bone, palatal lining, nasal lining, skin and soft tissue and it must fit into the complicated three-dimensional shape of the defect (1).

The free flaps most commonly used in midfacial reconstruction, representing the current flaps of choice, are Rectus abdominis flap (RA), Latissimus dorsi, Radial 
forearm flap, Scapula and Fibula flap (4, 8-10). These flaps have large-diameter vessels and their own distinctive characteristics with regard to the relative ratio of skin to soft-tissue bulk, satisfying midfacial soft tissue requirements $(2,6,7)$. The choice of flap is dictated by the volume of the defect and skin-surface area requirements (8).

These flaps can all be transplanted with minimal donor deformity.

In patients with type II subtotal maxillectomy defects the reconstruction took place with an ORFF folded into a sandwich (Fig. 1). The defect resulting from the resection of the lower five walls of the maxilla is characterised by a medium surface-area-to-volume ratio (1). The reconstruction with ORFF sandwich flap provided anterior projection, support for the upper lip, palatal and nasal lining $(7,23)$.
In patients with type IIIB total maxillary defects with orbital exenteration the reconstruction was possible with RA flap (Fig. 2). In these extensive defects (large volume and large surface defects) closure of the exposed anterior skull base as well as closure of the oronasal communication was required (1). The RA flap was designed with 3 skin islands for the closure of palate, reconstruction of the lateral nasal wall and restoration of the external skin.

We virtually never required 2 flaps for the reconstruction (24), and nonvascularized bone grafts are not used primarily. All large bone defects were reconstructed primarily with vascularized bone flaps. In the reconstruction of midface defects the restoration of lost form and function is crucial in order that the patients can function with normalcy and socialize freely postoperatively (25).
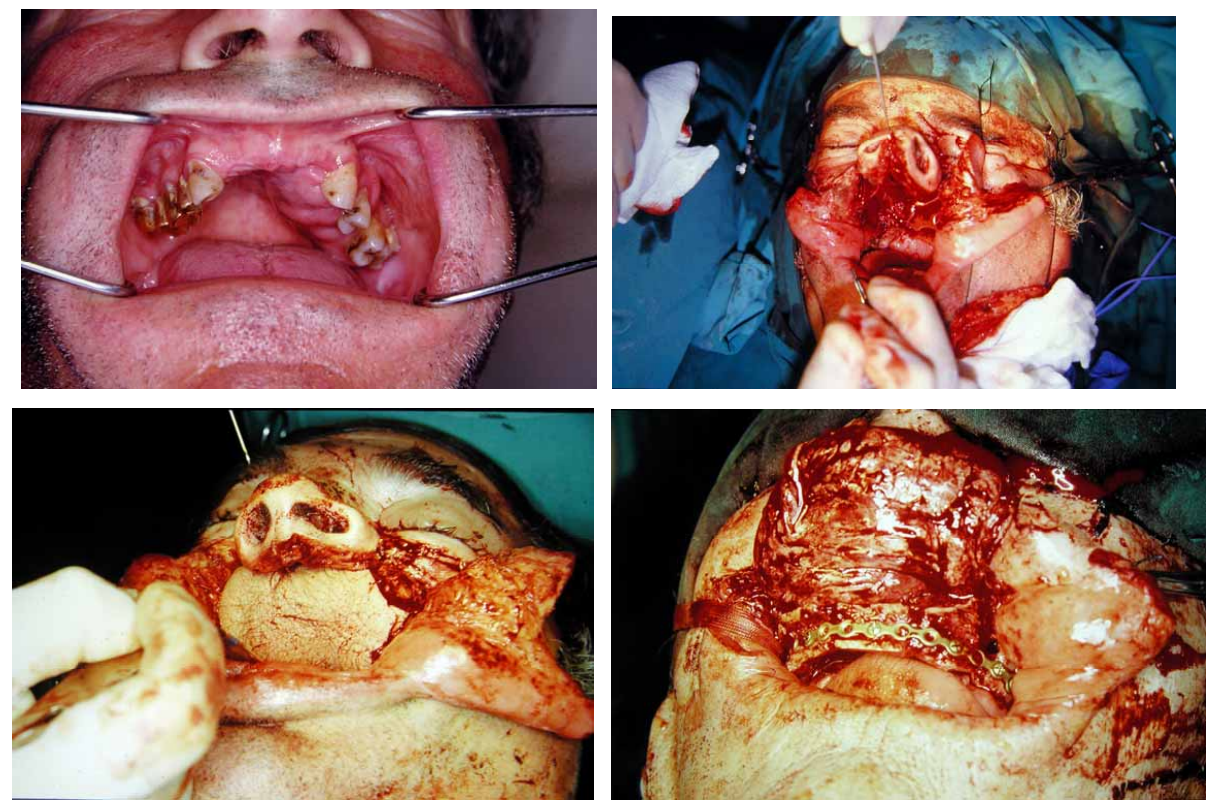

Fig. 1. (Above left) A 65-year old man (KK) with an adenocystic carcinoma of the upper jaw. (Above right) Intraoperative view

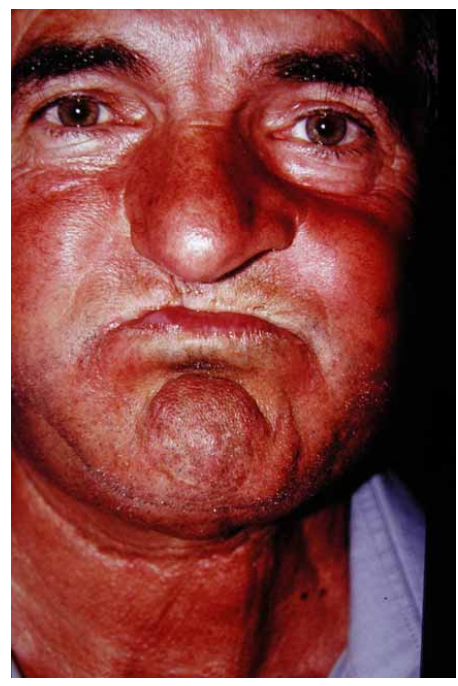
immediately following bilateral maxillectomy for tumour resection (Type II defect). (Center) Reconstruction of the defect was performed using ORFF sandwich flap for intraoral/palatal lining, rigidly fixed to remaining maxillary tubercles. (Below) Postoperative result at six months, demonstrating an acceptable aesthetic result with good maxillary contour, excellent oral competence, near normal speech and regular diet. Note intraoral skin island.

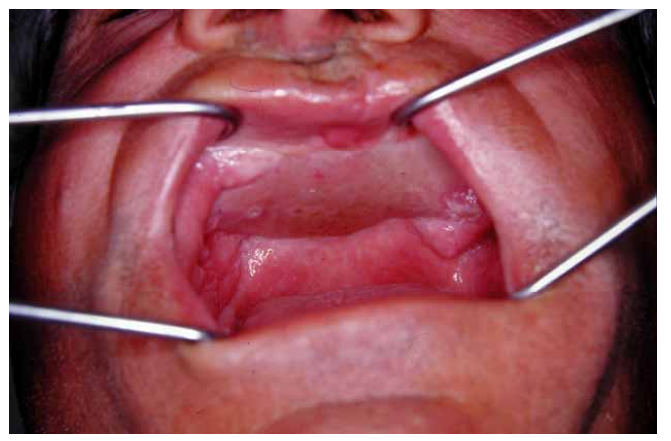



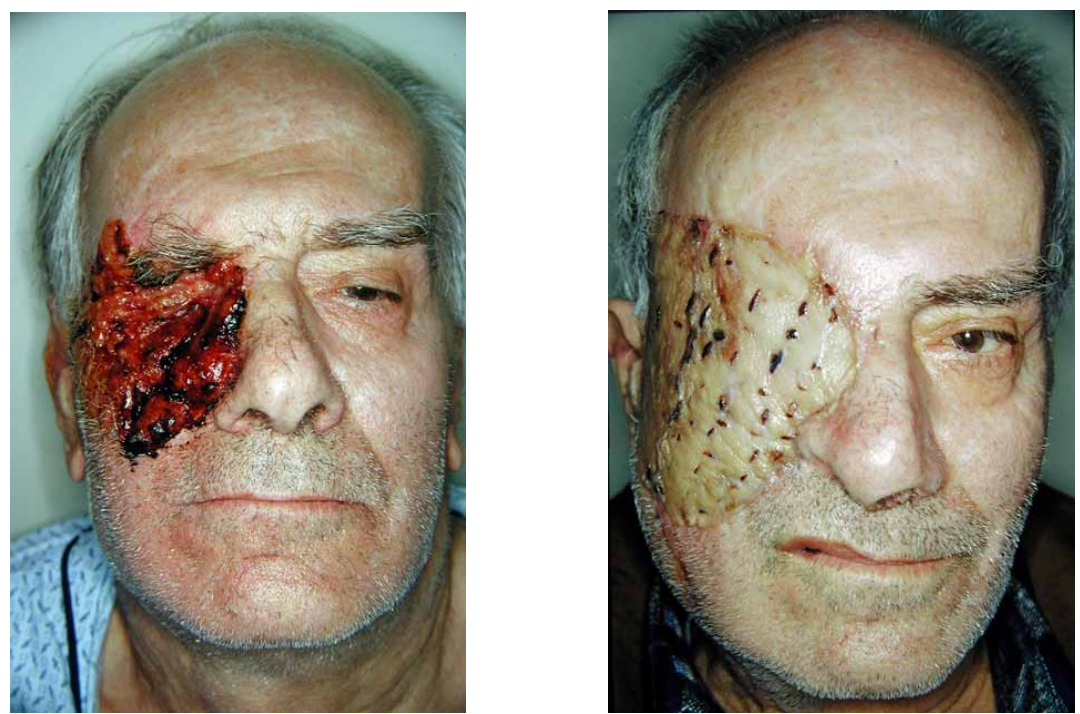

Fig. 2. (Left) A 60-year old man (AN) with a neglected squamous cell carcinoma of the right medial canthus. (Right) Reconstruction of Type IIIB defect was performed using RA flap for obliteration of the maxillary sinus and reconstruction of the palate (postoperative result at one month).

The functional restoration regarding the speech, mastication, and swallowing was in almost all our cases satisfactory.

The speech function of the patients varied postoperatively from normal or near normal to intelligible. In patients with a defect involving the palate, a flap skin island was always used for the palatal closure and not an obturator. Additionally, in all of our patients osseointegrated implants were not applied, while a denture fitting was difficult. Despite that, the patients were able to speak well and eat soft solids without problems. All patients were discharged without feeding tubes.

All 3 patients with resection and reconstruction of the oral commissure had good oral competence. They were able to retain both solid and liquid food inside the oral cavity postoperatively. A mild microstomia was developed in one of them mainly because of postoperative radiotherapy but no commissuroplasty was necessary.

Most patients with head and neck carcinoma are almost indifferent to aesthetic consequences of ablative cancer surgery and subsequent reconstruction, such as contour deformity.

In general, aesthetic results varied from fair to good mainly because of poor colour match and scars in cases of external skin replacement as well as because of variability in contour or facial asymmetry. In case of one patient (MA) with a total rhinectomy a prosthetic rehabilitation with a nasal prosthesis was recommended. The immediate postoperative complications were minimal and were easily treated.

In general, the results obtained with free tissue transfer were satisfactory, and no other major procedure was necessary.
In conclusion, reconstruction of maxillectomy defects is demanding, requiring a major surgical intervention and a variety of techniques have been proposed in order to maximize postoperative function as well as aesthetic outcome in these patients. According to the current trend, free flaps represent the reconstructive option of choice for midfacial defects, since these patients who have frequently a reduced life expectancy need a rapid and reliable reconstructive method in order to maximally improve their quality of life. The results of our small series of experiences with this reconstructive method clearly support the effectiveness of free microvascular tissue transfer in immediate midface reconstruction, in terms of aesthetic and functional rehabilitation of these patients.

\section{References}

1. Cordeiro PG, Santamaria E. A classification system and algorithm for reconstruction of maxillectomy and midfacial defects. Plast Reconstr Surg. 2000;105:2331-46.

2. Blackwell KE. Update on microvascular free tissue transfer: new trends and applications. Curr Opin Otolaryngol Head Neck Surg.2000;8:294-299.

3. Kyutoku S, Tsuji H, Inoue T, Kawakami K, Han F, Ogawa Y. Experience with the rectus abdominis myocutaneous flap with vascularized hard tissue for immediate orbitofacial reconstruction. Plast Reconstr Surg. 1999;103:395-402.

4. Gurtner GC, Evans GR. Advances in head and neck reconstruction. Plast Reconstr Surg. 2000;106:672-82.

5. Mast BA. Functional outcomes of microsurgical reconstruction of delayed complications following head and neck cancer ablation. Ann Plast Surg. 1999;42:40-5.

6. Shusterman MA. Reconstructionof total maxillectomy defects with preservation of the orbital contents (Discussion). Plast Reconstr Surg. 1998;101:1885.

7. Cordeiro PG, Bacilious N, Schantz S, Spiro R. The radial forearm osteocutaneous "sandwich" free flap for reconstruction of the 
bilateral subtotal maxillectomy defect. Ann Plast Surg. 1998;40:397402.

8. Foster RD, Anthony JP, Singer MI, Kaplan MJ, Pogrel MA, Mathes SJ. Reconstruction of complex midfacial defects. Plast Reconstr Surg. 1997;99:1555-65.

9. Kazaoka Y, Shinohara A, Yokou K, Hasegawa T. Functional reconstruction after a total maxillectomy using a fibula osteocutaneous flap with osseointegrated implants. Plast Reconstr Surg. 1999;103:1244-6.

10. Hidalgo DA, Disa JJ, Cordeiro PG, Hu QY. A review of 716 consecutive free flaps for oncologic surgical defects: refinement in donorsite selection and technique. Plast Reconstr Surg. 1998;102:722-32.

11. Brown JS. Deep circumflex iliac artery free flap with internal oblique muscle as a new method of immediate reconstruction of maxillectomy defect. Head Neck. 1996;18:412-21.

12. Stavrianos SD, Camilleri IG, McLean NR, Piggot TA, Kelly CG, Soames JV. Malignant tumours of the maxillary complex: an 18-year review. Br J Plast Surg. 1998;51:584-8.

13. Schliephake H. Revascularized tissue transfer for the repair of complex midfacial defects in oncologic patients. J Oral Maxillofac Surg. 2000;58:1212-8.

14. Olsen KD, Meland NB, Ebersold MJ, Bartley GB, Garrity JA. Extensive defects of the sino-orbital region. Results with microvascular reconstruction. Arch Otolaryngol Head Neck Surg. 1992;118:82833.

15. Cordeiro PG, Santamaria E, Kraus DH, Strong EW, Shah JP. Reconstruction of total maxillectomy defects with preservation of the orbital contents. Plast Reconstr Surg. 1998;102:1874-84.

16. Yamamoto Y, Minakawa H, Kawashima K, Furukawa H, Sugihara T, Nohira K. Role of buttress reconstruction in zygomaticomaxillary skeletal defects. Plast Reconstr Surg. 1998;101:943-50.

17. Spiro RH, Strong EW, Shah JP. Maxillectomy and its classification. Head Neck. 1997;19:309-14.

18. Coleman JJ 3rd. Osseous reconstruction of the midface and orbits. Clin Plast Surg. 1994;21:113-24.

19. Shestak KC, Schusterman MA, Jones NF, Janecka IP, Sekhar LN, Johnson JT. Immediate microvascular reconstruction of combined palatal and midfacial defects. Am J Surg. 1988;156:252-5.

20. Swartz WM, Banis JC, Newton ED, Ramasastry SS, Jones NF, Acland R. The osteocutaneous scapular flap for mandibular and maxillary reconstruction. Plast Reconstr Surg. 1986;77:530-45.

21. Wells MD, Luce EA. Reconstruction of midfacial defects after surgical resection of malignancies. Clin Plast Surg. 1995;22:79-89.

22. Cordeiro PG, Santamaria E. The extended, pedicled rectus abdominis free tissue transfer for head and neck reconstruction. Ann Plast Surg. 1997;39:53-9.

23. Lacombe V, Blackwell KE. Radial forearm free flap for soft palate reconstruction. Arch Facial Plast Surg. 1999;1:130-2.

24. Wei FC, Demirkan F, Chen HC, Chen IH, Liao CT, Hau SP. Management of secondary soft-tissue deficits following microsurgical head and neck reconstruction by means of another free flap. Plast Reconstr Surg. 1999;103:1158-66.

25. Wei FC, Demirkan F, Chen HC, Chen IH, Liao CT, Hau SP. Management of secondary soft-tissue deficits following microsurgical head and neck reconstruction by means of another free flap. Plast Reconstr Surg. 1999 103:1158-66. 